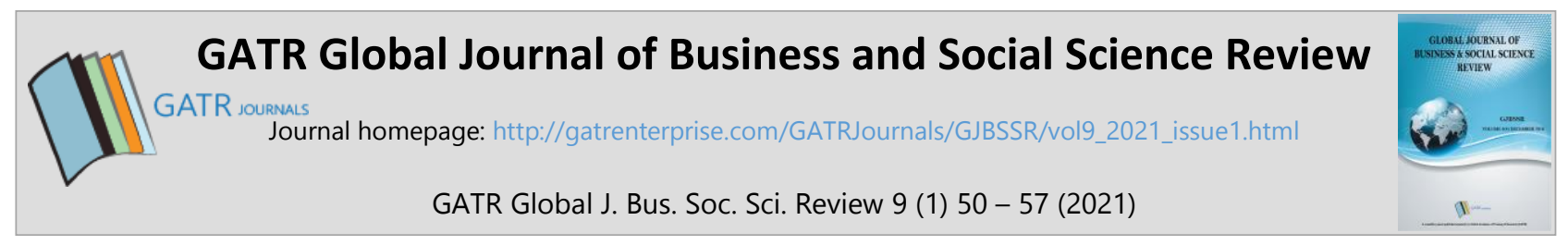

\title{
Sexual Harassment Deterrent Mechanism to Safeguard the Well- Being of Sports Practitioners
}

\author{
Sharifah Syahirah ${ }^{1 *}$,Syarifah Fathynah $^{2}$, Bahiyah Abdul Hamid ${ }^{3}$, \\ Habibah Ismail ${ }^{4}$, Fadilah Puteh ${ }^{5}$ \\ ${ }^{1}$ Kolej Universiti Poly-Tech MARA (KUPTM), 68000 Kuala Lumpur, Malaysia \\ ${ }^{2}$ National Sports Institution (ISN), 57000 Bukit Jalil, Malaysia \\ ${ }^{3}$ Universiti Kebangsaan Malaysia (UKM), 43600 Bangi, Malaysia \\ ${ }^{4}$ Universiti Sains Islam Malaysia (USIM), 71800 Nilai, Malaysia \\ ${ }^{5}$ Universiti Teknologi MARA (UiTM), 40450 Shah Alam, Malaysia
}

\begin{abstract}
Objective - This article attempts to discuss an on-going sexual harassment deterrent initiative in safeguarding the well-being of sports practitioners in Malaysia.

Methodology/Technique - The primary data used in this article is taken from a focus group session which consisted of a total of 35 participants. The main objective of this article is to discuss the results, specifically the recommendations made by focus group participants which consisted of government officers, members of NGOs, sports experts, and sports practitioners. The focus group participants firstly pin-pointed the inadequacy of current deterrent mechanisms that have failed to protect Malaysian athletes from sexual harassment such that more often than not many cases have been unreported or have simply been dismissed altogether. Following this, suggestions and recommendations were put forward by the focus group participants to improve on the mechanisms that would ensure a safe and supportive environment for all Malaysians in sport in order to eliminate all forms of sexual harassment, abuse, and exploitation.

Finding - Taking into consideration the suggestions and recommendations put forth by the focus group this paper suggests a 4Ps framework in order to eliminate all forms of sexual harassment and abuse in sport.
\end{abstract}

Type of Paper: Empirical.

JEL Classification: I310, Z32, Z280.

Keywords: Safeguard; Well-being; Sports Practitioners; Sexual Harassment; Deterrent Mechanism

Reference to this paper should be made as follows: Syahirah, S; Fathynah, S; Hamid, B.A; Ismail, H; Puteh, F. (2021). Sexual Harassment Deterrent Mechanism to Safeguard the Well-Being of Sports Practitioners, GATR Global J. Bus. Soc. Sci. Review, 9(1): 50 - 57. https://doi.org/10.35609/gjbssr.2021.9.1(6)

\section{Introduction}

Established in 2016 under the Ministry of Youth and Sports Malaysia, the National Sports Institute, locally known as Institut Sukan Negara (ISN), is the responsible body in Malaysia that drives the development of science, medical and technology in national sports.

\footnotetext{
* Paper Info: Revised: December 22, 2020

Accepted: March 31, 2021

* Corresponding author: Sharifah Syahirah

E-mail: shsyahirah@kuptm.edu.my

Affiliation: Kolej Universiti Poly-Tech MARA (KUPTM), 68000 Kuala Lumpur, Malaysia
} 
The ISN was set-up to create an environment which influences, supports and ensures that talented Malaysian athletes will achieve sustained levels of excellence in elite sports. Amongst the functions of ISN is to be an information, resource and reference centre for sports science, sports medicine as well as for issues and cases related to sexual harassment and abuse in sport.

Sexual harassment and abuse in sport are widely discussed in western countries. However, generally in Southeast Asia, these issues due to social and cultural gatekeeping have only until recently become publicly and widely discussed as more people become aware of the detrimental effects of sexual harassment and abuse in sport. The prevalence of sexual harassment cases transpires in almost all sports at all levels regardless whether in elite or other types of sports.

In Malaysia, validated research indicates that sexual harassment and abuse is widespread not just in sports but in many settings such as business, education, medical and many other settings. Due to a series of sexual harassment and abuse cases reported in Malaysia, the government has agreed to draft the Anti-Sexual Harassment Act which will be tabled in Parliament in order to promote safe and supportive environments, free from harassment for its citizens. With respect to this issue, the ISN has taken proactive action in conducting a series of focus group sessions, seminars and surveys to examine sexual harassment in sport among sports practitioners particularly related to Malaysian athletes as a first step to assist the Ministry of Youth and Sports specifically and the government generally in developing policies and procedures for the prevention and elimination of sexual harassment and abuse in sport.

Therefore, this article attempts to discuss the ongoing sexual harassment deterrent initiatives in safeguarding the well-being of sports practitioners in Malaysia. The main objective of this article is to discuss the findings, specifically the recommendations made by focus group participants which included government officers, representatives of NGOs, sports experts and sports practitioners.

\section{Literature Review}

The literature review is divided into 2 themes namely (i) the prevalence of sexual harassment in sport; and (ii) prevention measures or deterrent initiatives to eliminate all form of sexual harassment and abuse in sport. In Malaysia, there is a dearth of studies related to the occurrence of sexual harassment in sport; Fathynah and Syahirah (2015) and Fathynah et. al., (2017) are the exception to this issue. They found that about $10 \%$ to $16 \%$ sports practitioners, particularly elite athletes, have experienced certain forms of sexual harassment mainly verbal and physical harassment. Their findings concur with studies conducted by Christian and Phin (2017), Murnen and Kohlman (2007), Parent and Bannon (2012), Murphy (2019), Yucel et. al. (2014), Appak and Sarpong (2015), Fejgin and Hanegby (2001), Auweele et. al. (2014), Hill, Burch-Ragan and Yates (2001) and Mewett and Foffoletti (2008).

Meanwhile, contrary to popular belief that coaches are perpetrators of sexual harassment and abuse, Hill, Burch-Ragan and Yates (2001), Murnen and Kohlman (2007), O'Brien et. al. (2012), and Yucel et. al. (2014) found that peer athletes have a high tendency to become sexual perpetrators. Further, according to Fasting, Brackenridge and Sungot-Borgen (2003), peer athletes harass athletes more than coaches. Because of the higher proportion of males in power positions in sport, it is not surprising to find research findings that report the prevalence of male perpetrators of sexual harassment and abuse (Fasting et. al., 2010). However, it was found that males are not solely the perpetrators of sexual harassment and abuse, females are also perpetrators but to a lesser extent (Brackenridge et. al., 2008).

An extensive review of literature on the deterrent initiatives or preventive measures on sexual harassment indicate several feasible strategies. Melnick (1992) affirms that male athletes need to be educated so that they can understand that sports are not exclusively masculine spheres but instead are spheres in which they can explore skills and make friends. This view is in tandem with Hayhurst et. al., (2014) who argue that women's involvement in martial arts is a good platform to equip them with empowerment, confidence and the ability to fight back at any unwanted moves that may lead towards sexual harassment. 
Melnick (1992), Fried (1996), Osborne (2013), Johansson, Kentta and Andersen (2016) and Jaime et. al., (2018) are of the view that structured education and training programs that prohibits sex-based discrimination and violence in sport involving schools, coaches and athletes help to prevent sexual harassment in sport. Melnick (1992), Fried (1996), Velasquez (1998), Cullitan (2010) and Donnelly et. al., (2016) point out that a standard policy and clear interpretation of law that prohibits any sex-based discrimination is needed to increase accountability and responsibility of sports institutions in enforcing the laws and policies. Meanwhile, Espinoza and Cunnigham (2011) call for proactive, diversified work culture setting among coaches that would provide better preventive measures for sexual harassment. It is also noted by Teasley and Gill (2015) that sexual harassment in school sports can be prevented and handled professionally with the involvement of school social workers through their experience, skills and emotional support.

\section{Research Methodology}

A qualitative method has been applied by using feminist and social constructivist lenses. The design of this study was cross sectional research in which the data was collected within a specific period of time. The data is collected through focus group session (FGS) comprised of 35 participants from sports institutions, enforcement officers, civil society representatives, athletes and related government agencies. Thus, a convenience sample was utilized, i.e., the participants of the study were purposefully selected as participants because the researchers of the study were confident that they represented the best in experiences dealing with issues related to sexual harassment, violence and abuse including law and enforcement, policy development and governance and were equipped to provide the most accurate information to address the objectives of the study (Creswell, 2013). The FGS was conducted face-to-face on April 2019. In the FGS, the participants were divided into 3 groups and discussed the list of semi-structured questions prepared by the researchers of this study within a given framework. Each group consisted of 10 to 13 participants, 1 rapporteur and 2 facilitators. Data gathered from the FGS was analyzed using the thematic analysis technique.

\section{Results and Discussion}

The findings of the FGS yielded 5 dimensions of recommendations as follows: 4.1) standard operating procedure, 4.2) culture, mindset and stereotyping, 4.3) support and resources, 4.4) awareness and internalization, and 4.5) data and statistics.

\subsection{Standard Operating Procedure (SOP) and Mechanism}

For the SOP and mechanism, 7 recommendations were highlighted during the focus group discussion. They are:

i) policy and platform

ii) the use of existing law (Whistle Blower Protection Act- Act 711)

iii) protection and support

iv) visibility and accessibility of policy and SOPs

v) periodic review of ethics and code of conducts for coaches, athletes, and sports officers

vi) monitoring and follow up, and vii) impact assessment

The first mechanism is to introduce a deterrent policy and a safe platform (safe sports policy) for sports practitioners to report and get protection as victims or act as whistle blowers. The second recommendation is to ensure that the existing laws such as the Whistle Blower Protection Act-Act 711 are incorporated in the deterrent policy. The third recommendation is to ensure the protection and support of whistle blowers and victims. The fourth recommendation is related to visibility and accessibility of policy and SOPs. All SOPs related to the policy and laws related to the prevention and elimination of sexual harassment must be widely

GATR Global J. Bus. Soc. Sci. Review 9 (1) 50 - 57 (2021) 
circulated to enhance public awareness of its existence and what is entailed in its implementation. Fifth, the members of the focus group discussion also suggest that the policy and SOPs need to be regularly reviewed and the implementations of Ethics and Code of Conduct for coaches and Ethics and Code of Conduct for athletes should be revisited and reviewed periodically by coaches, athletes, and sports officers.

The sixth mechanism is based on the suggestion that the policy or code of conduct need to be monitored closely particularly on its implementation. The lack of supervision and regulation have been cited by a research by Donnelly et. al., (2016) about prevention of sexual harassments within sport organizations in Canada to be the factors that have led to less effective implementation and this finding is supported by Fathynah et. al., (2015) and Sharifah Syahirah et. al., (2020). The seventh recommendation is on the effectiveness of the policy and the SOP needs to be evaluated from time to time, i.e., ensure monitoring and impact assessment of policy. Some of these findings are parallel to Mountjou et. al. (2015) findings (outlined 8 safeguarding initiatives that they recommended for the IOC youth athlete development model.

\subsection{Culture, Mindset and Gender Sensitive Practice}

In order to overcome the challenges related to culture, mindset and gender sensitive practices, 2 initiatives were recommended: 1) initiative to change the culture of sexism, stereotyping and power structures that encourage sexual harassment, and 2) cultivate the culture of respect which include all target groups. For the first initiative, it was suggested that cultures and power structures which perpetuate sexual harassment and sexual abuse should be changed. Institutions should take the initiative to improve awareness about sexism and stereotypes through campaigns and poster creation. Institutions also need to provide initiatives that would adequately protect sexual harassment victims and whistle blowers.

The second initiative involves the cultivation of the culture of respect. It was recommended for institutions to make sure that the culture of respect and zero tolerance towards any form of sexual harassment to include all stakeholders including parents, coaches, management and athletes. Based on a past study, a proactive initiative that could be emulated in Malaysia; a program called "Coaching Boys into Men" where the coaches are required to integrate messages related to violence prevention were found to be effective in changing school athletes' behaviors and mindsets (Miller et. al., 2013). This success was attributed to the fact that athletes trust and respect their coaches, i.e., an authoritative figure.

\subsection{Support and Resources}

Five recommendations related to support and resources were brought forward. They are as follows:

(i) employing trained manpower and human resource to manage sexual harassment cases

(ii) adopting inclusive involvement policy

(iii) appointing independent committee members to sit in as panel to manage and investigate sexual harassment cases

(iv) providing facilities and infrastructure

(v) adopting mandatory application of the zero-tolerance practice and code of conduct by all sports organizations.

First, more qualified officers to manage sexual harassment cases as well as designated multimedia officers need to be appointed and should be in charge of information and database. The second and third recommendations relate to the appointment of committee members who manage and investigate sexual harassment cases. The members in the focus group discussion proposed the appointment of independent committee members who should represent all stakeholders including those from civil society which includes a committee observer from the affected community. 
It is important to "choose people who is neutral to handle the case/ issue" (From Group 2- Focus Group Discussion- Rapporteur's notes). The fourth recommendation involves the creation of a one-stop center to manage all sports-related problems including the management of sexual harassment cases and activities and programs to prevent sexual harassment in sport. Finally, it was suggested that the standardization of the code of conduct along with zero-tolerance practices should be adopted by all Malaysian sports organizations. This standardization also involves rules and regulations among agencies. The kinds of support and resources discussed above should be made accessible (if not available) to all sports organizations.

\subsection{Awareness and Internalization}

Two recommendations were suggested under this category. The first recommendation is to amplify sexual harassment awareness campaigns supported by all related agencies. Coordinated involvement of institutions, businesses and NGOs is needed especially through new media campaigns, i.e., through social media. As mentioned in the focus group discussion, "Awareness needs more campaign. Work with ISN, Department of Women's Development (JPW) should have the connection" (From Group 1- Focus Group DiscussionRapporteur's notes).

Recommendations also include utilising catchy notices, posters and special messages that target a variety of audiences not only sports officials but also coaches, parents/caretakers and the public. These efforts will certainly fuel wider conversations and assist to inform all that sexual harassment is inexcusable. Currently, the key stakeholders such as parents and caretakers, athletes and sports managers are usually left out in receiving valuable informative materials and documents related to sexual harassment, sexual abuse and formal definitions of boundaries (Brackenridge et. al., 2010; Global Sports Development Organization, 2014; and Sharifah Syahirah et. al., 2020). This current practice creates an information gap that jeopardises the creation of understanding as to what constitutes sexual harassment at both the personal and societal level as well as it hinders efforts to empower victims of sexual harassment (Bjornseth \& Szabo, 2018).

The second recommendation in this category is related to training and courses to equip existing sports officials with knowledge and skills in order to cater to the prevention of sexual harassment and to the efficient management of sexual harassment cases. Brackenbridge et. al. (2010) and Global Sports Development Organization (2014) have ascertained that education and training are lacking for several key holder groups, including athletes, parents, policymakers, support personnel, officials and sports managers. It is necessary to make these courses/trainings mandatory as one of Key Performance Index items for their job appraisals as mentioned in the focus group discussion; "Raise awareness periodically e.g., sexual harassment training during orientation in Sports institution for all" (From Group 3- Focus Group DiscussionRapporteur's notes).

Sports personnel, officers and administrators should be equipped with legal literacy, institutional accountability, witness training, investigational skills, counselling and administrational management. Besides gender sensitization training and understanding of sexism in society, clear understanding of the culture of toxic (or hostile) masculinity that is prevalent in sport culture needs to be targeted for intervention. This awareness should start early and be incorporated into the education system via course modules and personal development programmes. The concepts and culture of respect, honour and integrity needs to be highlighted, valued and nurtured in the sport milieu (Abrams \& Bartlett, 2019).

\subsection{The Management and Collection of Data and Statistics}

In this category, 2 recommendations are presented. Parent and Demers (2011) and Syahirah et. al. (2020) concluded in their study that there is little pre-employment and pre-recruiting screening in the sports world. Hence, the first recommendation involves the development of an information database system with records of those involved in previous sexual harassment cases to assist in background checks and screening purposes. Contrary to previous belief of coach as perpetrator, new research findings suggest that peer- 
athletes/teammates may precede the coach as perpetrators of sexual harassment and sexual violence at the lower levels of competitions (Fathynah et. al., 2015, 2017; Bjornseth \& Szabo 2018). It is found that coaches are more frequently the perpetrators at higher levels of competitions. Such a database will help the screening process during athlete, support and volunteer personnel recruitment and staff hiring to minimise sexual harassment and sexual abuse and to ensure the safety and wellbeing of all in the sports sector (Parent \& Demers, 2010; Global Sports Development Organization, 2014).

The second recommendation refers to data collection with regards to mental health as part of the contentspecific approach to sexual harassment comprehensive prevention, risk assessment and treatment. Periodical mental health assessment (for instance, Child Sexual Abuse (CSA) and behavioural and psychological consequences of CSA) and psychometric assessments (for instance, to assess the psychological constructs in sexual offenders or to understand attitudes toward reporting sexual harassment in the workplace, and so on) should be carried out on all sports officers, coaches and athletes. It is critical to address and remediate prominent issues in today's sport landscape.

The focus group respondents suggest that such assessment should be done in collaboration with several ministries. e.g., Ministry of Youth and Sports, Ministry of Women, Family and Community Development and Ministry of Health. The third recommendation is to introduce the use of applications specifically smart phone applications to manage and assist in sexual harassment reporting. A user-friendly application should be created for reporting and collecting data via smart phone, and that it should be made accessible to the public. The use of such applications in reporting and disclosure can assist to mitigate the fear of disclosure that many victims and witnesses of sexual harassment have to grapple with.

\section{Conclusion}

The findings, specifically recommendations and discussions with regard to sexual harassment and abuse in sport in Malaysia gathered from a focus group discussion, found in this article show that there is a dire need to introduce a comprehensive framework to safeguard sports practitioners well-being especially against all forms of sexual harassment and abuse in Malaysia. Therefore, for future research, we suggest a 4Ps framework which consists of prevention, procedure, protection and penalty dimensions to address all recommendations discussed in this paper. From the findings of the focus group discussion that pin-pointed the limitations of current deterrent mechanisms to safeguard sports practitioners, particularly athletes from sexual harassment and abuse, it is obvious that Malaysia needs a systematic approach, i.e. deterrent policies, effective procedures, protection of the victims as well as third parties, and penalty against perpetuators.

Here, a national Act on anti- sexual harassment especially in sport is needed as a source of power to implement various preventive and elimination of sexual harassment initiatives in various institutions. The findings of this study will assist the ISN, the Ministry of Youth and Sports and the Malaysian government in developing policies and procedures for the prevention and elimination of sexual harassment, abuse, violence and exploitation thus ensuring a supportive and secure environment for all sports practitioners in Malaysia.

\section{Acknowledgements}

This research is funded by National Sports Institute of Malaysia (ISN) under Grant No. ISNRP005/2018. Thank you for the continuous support of research related to gender equality in sport. Thank you to our two young and energetic research assistants Ms. Nurhidayah Abdul Rahman and Ms. Rashidah Roseli for excellent commitment to this research project. Last but not least, we would like to extend our heartiest gratitude to the Chief Executive Officer of ISN, Mr. Ahmad Faezal Md Ramli for officiating the focus group workshop as well as to all experts involved. 


\section{References}

Abrams, M., \& Bartlett, M. L. (2019). \# SportToo: implications of and best practice for the\# MeToo movement in sport. Journal of Clinical Sport Psychology, 13(2), 243-258.doi:10.1123/JCSP.2018-0065

Apaak, D., \& Sarpong, E. O. (2015). Knowledge level and incidence of sexual harassment in sports: Views of Ghanaian female university athletes. Journal of Educational and Social Research, 5(3), 121. DOI: 10.5901/jesr.2015.v5n3p121

Auweele, Y. V., Opdenacker, J., Vertommen, T., Boen, F., Van Niekerk, L., De Martelaer, K., \& De Cuyper, B. (2008). Unwanted sexual experiences in sport: Perceptions and reported prevalence among Flemish female student-athletes. International Journal of Sport and Exercise Psychology, 6(4), 354-365.DOI: 10.1080/1612197X.2008.9671879

Bjørnseth, I., \& Szabo, A. (2018). Sexual violence against children in sports and exercise: a systematic literature review. Journal of child sexual abuse, 27(4), 365-385.doi.org/10.1080/10538712.2018.1477222

Brackenridge, C. H., Bishopp, D., Moussalli, S., \& Tapp, J. (2008). The characteristics of sexual abuse in sport: A multidimensional scaling analysis of events described in media reports. International Journal of Sport and Exercise Psychology, 6(4), 385-406.DOI: 10.1080/1612197X.2008.9671881

Brackenridge, C.H, Fasting, K., Kirby, S.L., \& Leahy, T. (2010). Protecting Children from Violence in Sport: A Review with a Focus on Industrialised Countries. United Nations Children's Fund. Florence, Italy: UNICEF Innocenti Research Centre, 1-54. Retrieved from https://www.unicef-irc.org/publications/pdf/violence_in_sport.pdf

Christian, E. I., \& Phin, T. S. (2017). Marital status as correlate of sexual harassment experiences among athletes in southern nigerian universities. British Journal of Education, 5(12), 60-68. Retrieved from http://www.eajournals.org/wp-content/uploads/Marital-Status-as-Correlate-of-Sexual-Harassment-Experiences-amongAthletes-in-Southern-Nigerian-Universities-edited.pdf

Creswell, J. W., \& Poth, C. N. (2016). Qualitative inquiry and research design: Choosing among five approaches. Sage publications.

Cullitan, C. M. (2010). I'm His Coach, Not His Father-A Title IX Analysis of Sexual Harassment in College Sports. Tex. Rev. Ent. \& Sports L., 12, 53. Retrieved from https://texashistory.unt.edu/ark:/67531/metapth638897/m2/1/high_res_d/UNT-0029-0011.pdf

Donnelly, P., Kerr, G., Heron, A., \& DiCarlo, D. (2016). Protecting youth in sport: An examination of harassment policies. International Journal of Sport Policy and Politics, 8(1), 33-50. https://doi.org/10.1080/19406940.2014.958180

Espinoza, C., \& Cunningham, G. (2011). Relationships Among Sexual Harassment, Gender, and Diversity Culture in High School Athletics. Journal for the Study of Sports and Athletes in Education, 5(1), 85-104. https://doi.org/10.1179/ssa.2011.5.1.85

Fasting, K., Brackenridge, C., \& Sundgot-Borgen, J. (2003). Experiences of sexual harassment and abuse among Norwegian elite female athletes and nonathletes. Research quarterly for exercise and sport, 74(1), 84-97. https://doi.org/10.1080/02701367.2003.10609067

Fasting, K., Chroni, S., Hervik, S. E., \& Knorre, N. (2011). Sexual harassment in sport toward females in three European countries. International review for the sociology of sport, 46(1), 76-89.DOI:10.1177/1012690210376295

Fejgin, N., \& Hanegby, R. (2001). Gender and cultural bias in perceptions of sexual harassment in sport. International Review for the sociology of sport, 36(4), 459-478. https://doi.org/10.1177/101269001036004006

Fried, G. B. (1996). Unsportsmanlike contact: strategies for reducing sexual assaults in youth sports. J. Legal Aspects Sport, 6, 155.DOI: https://doi.org/10.1123/jlas.6.3.155

SS, S. F., \& SS, S. S. (2015). The occurrence of sexual harassment among sports practitioners in Bukit Jalil, Kuala Lumpur. Procedia-Social and Behavioral Sciences, 211, 917-923. https://doi.org/10.1016/j.sbspro.2015.11.121

FATHYNAH, S. S., SYAHIRAH, S. S., \& FAIZAL, L. M. PREVALENCE OF SEXUAL HARASSMENT INsPoRTs.: MALAYSIAN.

Global Sports Development Organization. (2014, April 29). Preventing Sexual Abuse in Sport. Retrieved from https//www. globalsportsdevelopment.org/2014/04/29/sexual -abuse-sport-prevention/pdf.

Hayhurst, L. M., MacNeill, M., Kidd, B., \& Knoppers, A. (2014, November). Gender relations, gender-based violence and sport for development and peace: Questions, concerns and cautions emerging from Uganda. In Women's Studies International Forum (Vol. 47, pp. 157-167). Pergamon. doi:10.1016/j.wsif.2014.07.011

Hill, K., Burch-Ragan, K. M., \& Yates, D. Y. (2001). Current and future issues and trends facing student athletes and athletic programs. New directions for student services, 93, 65-80. DOI: 10.1002/ss.6 
Jaime, M. C. D., McCauley, H. L., Tancredi, D. J., Decker, M. R., Silverman, J. G., O’Connor, B., \& Miller, E. (2018). Implementing a coach-delivered dating violence prevention program with high school athletes. Prevention science, 19(8), 1113-1122. doi:10.1007/s11121-018-0909-2

Johansson, S., Kenttä, G., \& Andersen, M. B. (2016). Desires and taboos: Sexual relationships between coaches and athletes. International journal of sports science \& coaching, 11(4), 589-598. doi:10.1177/1747954116654777

Melnick, M. (1992). Male athletes and sexual assault. Journal of Physical Education, Recreation \& Dance, 63(5), 3236.doi:10.1080/07303084.1992.10604186

Mewett, P., \& Toffoletti, K. (2008). Rogue men and predatory women: Female fans' perceptions of Australian footballers' sexual conduct. International Review for the Sociology of Sport, 43(2), 165180.doi:10.1177/1012690208095377

Mountjoy, M., Brackenridge, C., Arrington, M., Blauwet, C., Carska-Sheppard, A., Fasting, K., ... \& Budgett, R. (2016). International Olympic Committee consensus statement: harassment and abuse (non-accidental violence) in sport. British Journal of Sports Medicine, 50(17), 1019-1029.http://dx.doi.org/10.1136/bjsports-2016-096121

Murnen, S. K., \& Kohlman, M. H. (2007). Athletic participation, fraternity membership, and sexual aggression among college men: A meta-analytic review. Sex roles, 57(1-2), 145-157.doi:10.1007/s11199-007-9225-1

Murphy, W. F. (2019). Investigating the incidence of sexual assault in martial arts coaching using media reports. Digital Investigation, 30, 90-93. https://doi.org/10.1016/j.diin.2019.07.001

O’Brien, K. S., Kolt, G. S., Martens, M. P., Ruffman, T., Miller, P. G., \& Lynott, D. (2012). Alcohol-related aggression and antisocial behaviour in sportspeople/athletes. Journal of Science and Medicine in Sport, 15(4), 292-297. DOI: 10.1016/j.jsams.2011.10.008

Osborne, B. (2013). Eliminating sexual violence in schools: implications for athletics administrators in the United States. The International Sports Law Journal, 13(1-2), 9-17. doi:10.1007/s40318-013-0002-8

Parent, S., \& Bannon, J. (2012). Sexual abuse in sport: What about boys?. Children and Youth Services Review, 34(2), 354-359. https://doi.org/10.1016/j.childyouth.2011.11.004

Parent, S., \& Demers, G. (2011). Sexual abuse in sport: a model to prevent and protect athletes. Child Abuse Review, 20(2), 120-133. https://doi.org/10.1002/car.1135

Syahirah, S., SS, S. F., Melati, W. P., Puteh, F., Hamid, B. A., \& Ismail, H. (2020). Sexual harassment in sports: Risk factors analysis from a Malaysian perspective. International Journal of Psychosocial Rehabilitation. DOI: 10.37200/IJPR/V24I3/PR200833

Teasley, M. L., \& Gill, E. (2015). School sports, sexual abuse, and the utility of school social workers. Children \& schools, 37(1), 4-7. https://doi.org/10.1093/cs/cdu032

Velasquez, B. J. (1998). Sexual harassment: a concern for the athletic trainer. Journal of athletic training, 33(2), 171. Yücel, A. S., Korkmaz, M., Karataş, Ö., Hergüner, G., Yaman, Ç., \& Çatıkkaş, F. (2014). Determination of sexual harassment and abuse women athletes face in sports: A case study. 